\title{
The New Psychosocial Position Statement from the American Diabetes Association
}

\author{
An Expert Interview with Linda Siminerio \\ University of Pittsburgh Diabetes Institute, Pittsburgh, Pennsylvania, US
}

DOl: https://doi.org/10.17925/USE.2017.13.01.10

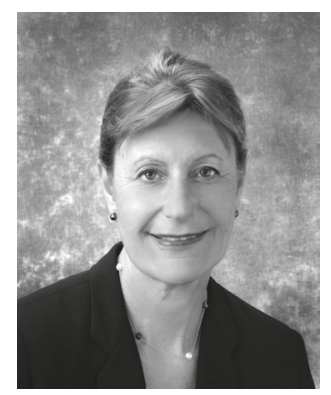

Linda Siminerio

Linda Siminerio is Professor of Medicine and Nursing at the University of Pittsburgh and has led a career in diabetes research and education. A nationally recognized expert on self-management education and care delivery models in both pediatric and adult populations, she serves as the principal investigator on numerous studies related to diabetes prevention and treatment. Dr siminerio served as President of Health Care and Education, American Diabetes Association and Senior Vice President, International Diabetes Federation (IDF). In these positions, she has organized and led national and international efforts on the development of programs, curricula and standards for diabetes education directed toward health professionals, patients and the community. Dr siminerio served as organizing chair for the International Diabetes Federation (IDF) World Diabetes Congress and the IDF translation research program, BRIDGES. She is currently Chair of the National Diabetes Education Program.

\section{Keywords}

Psychosocial, education, support, diabetes distress

Disclosure: Linda Siminerio has served on an advisory panel for Becton, Dickinson and Company. No funding has been received for the publication of this article. This is an expert interview and as such has not undergone the journal's standard peer review process.

Acknowledgements: Editorial assistance was provided by Catherine Amey, Freelance Medical Writer, supported by Touch Medical Media.

Authorship: All named authors meet the International Committee of Medical Journal Editors (ICMJE) criteria for authorship of this manuscript, take responsibility for the integrity of the work as a whole, and have given final approval to the version to be published.

Open Access: This article is published under the Creative Commons Attribution Noncommercial License, which permits any noncommercial use, distribution, adaptation, and reproduction provided the original author(s) and source are given appropriate credit. Received: March 20, 2017

Published Online: May 8, 2017

Citation: US Endocrinology, 2017;13(1):10-1

Corresponding Author: Linda Siminerio, Professor of Medicine and Nursing. University of Pittsburgh, Falk Medical Building, Room 570, 3601 Fifth Avenue, Pittsburgh PA 15213, US. E: simineriol@upmc.edu
D iabetes self-management education and support provides the foundation for helping people with diabetes to be able to navigate decisions and activities related to managing their life-long disease. Here, Linda Siminerio of the School of Medicine and Nursing, University of Pittsburgh, Pennsylvania, US, discusses psychological factors affecting people with diabetes, self-management and the multiple benefits of ongoing education and support.

\section{Q: What are some common psychological factors affecting people with diabetes?}

A number of people will experience diabetes distress, i.e., the stress with having to manage the lifelong and complex burden of the disease. Diabetes management involves medication, blood glucose testing, interpreting the results, eating healthily, and being active. It is important for clinicians to recognize this problem as well as detecting depression, anxiety, and disordered eating.

\section{Q: What are recent findings regarding diabetes self-management?}

We no longer believe that providing information alone is adequate. Instead, we need to ensure that patients receive ongoing diabetes self-management education and support, which forms the foundation of diabetes care. This requires both lifestyle and behavioral changes on the behalf of the patient. Results show these are associated with improvements, not only in clinical outcomes, but also in psychosocial aspects, such as quality of life, coping, and adherence to treatment.

\section{Q: What are some recommendations regarding psychosocial comorbidities, such as depression?}

Careful assessment is vital and clinicians must be attuned to the symptoms of depression, for example, and if they do recognize the symptoms, e.g. poor sleep and eating habits and poor engagement in social activities, clinicians need to address them with appropriate tools and therapies. It is important to differentiate between depression, for which antidepressants and therapy may be indicated, and diabetes distress. 


\section{Q: How can barriers to care be improved for people at lower socioeconomic levels?}

There is no simple answer, since the quality of healthcare provision depends on community and government support, environmental factors, costs, e.g., diabetes medications, blood glucose testing equipment, and newer technology, such as insulin pumps. Lack of healthy foods and the availability of cheaper junk foods may also be a barrier to be tackled.

\section{Q: What are the major challenges in terms of implementing these recommendations into routine clinical practice?}

Worldwide, there is agreement in the literature that patient self-management education and support is crucial, yet the number of people receiving this service is abysmal. It is a complex, global problem, involving financial, educational, and logistical barriers (such as access to transportation) that all need to be addressed to ensure high-quality care. $\square$

1. Powers M, Bardsley J, Cypress M, et al., Diabetes self-management education and support in type 2 diabetes. A joint position statement of the American Diabetes Association, the American Association of Diabetes Educators and the Academy of Nutrition and Dietetics. Available at: www.diabeteseducator.org/practice/practice-documents/practice-statements (accessed 20 March, 2017 ). 